\title{
Spatial, temporal and ontogenetic patterns of habitat use by coral reef fishes (Family Labridae)
}

\author{
Alison L. Green* \\ Marine Biology Department, James Cook University of North Queensland, Townsville, Queensland 4812, Australia
}

\begin{abstract}
The continuous reef tract on the semi-exposed side of Lizard Island, northern Great Barrier Reef, can be divided into 6 habitat zones, which are distinctly different in terms of their physical (depth, slope and wave exposure) and biological characteristics (percentage of living cover, percentage cover of each substratum type, substratum diversity and complexity). Sixty-four labrid species were found to use these habitat zones in 5 surveys conducted over 3 yr. Thirty-eight species (1804 individuals) were recorded in a single survey (area, $13500 \mathrm{~m}^{2}$ ). of which 8 were abundant ( $\mathrm{n}>5 \%$ of total number of individuals), 6 were common $(1 \%<n<5 \%$ of total) and 24 were rare $(n<1 \%$ of total). Seven of the abundant species showed strong patterns of habitat use, such that the assemblages of these species differed significantly among habitat zones ( $<<0.0001)$. Only 1 abundant species, Labroides dimidiatus, occurred in similar densities in all habitat zones. Depth appeared to be of overriding importance in determining habitat use, with most species occurring either in shallow or deep zones. Within depth ranges, the labrid assemblages differed among habitat zones in terms of the relative abundance of species. In contrast, no clear relationship was detected between labrid density or diversity and other habitat features such as percentage living substratum, substratum diversity or complexity. These patterns were consistent at each of 3 sites separated by $>1 \mathrm{~km}$ and over 3 yr and 2 seasons (summer and winter). Only 2 of the 8 abundant species showed different patterns of habitat use by adults and recruits, suggesting ontogenetic shifts in habitat use by these species. In contrast, the others showed no evidence of ontogenetic shifts in habitat use, inferring that recruitment patterns may be important in structuring patterns of habitat use by these species. Further studies are now required to test this hypothesis.
\end{abstract}

KEY WORDS: Distribution - Abundance Patterns - Processes - Recruitment - Ontogenetic change Habitat description - Visual census methods

\section{INTRODUCTION}

An important goal of reef fish ecology is to determine the processes that are important in structuring reef fish assemblages (see Doherty \& Williams 1988, Williams 1991). The first step toward understanding these processes is to obtain precise estimates of the distribution and abundance of the assemblages under study, at a scale which is relevant in space and time (Jones 1988, Mapstone \& Fowler 1988, Fowler 1990). The intention of this study was to describe the patterns of habitat use by reef fishes, and to examine the

\footnotetext{
- Present address: Department of Marine and Wildlife Resources, PO Box 3730, Pago Pago, American Samoa 96799
}

processes that may have been important in producing these patterns.

Previous studies have demonstrated that reef fishes show discontinuous distributions at a range of broad spatial scales on the Great Barrier Reef (hereafter GBR), from among reefs across the continental shelf (Williams 1982, Williams \& Hatcher 1983) to among exposures within reefs (Talbot \& Goldman 1972, Goldman \& Talbot 1976, Eckert 1985). However, little is known of the fine-scale patterns of distribution and abundance of fishes among habitat zones within exposures. The primary objective of this study was to describe temporal and spatial patterns of distribution and abundance of reef fishes among habitat zones. The second objective was to determine if patterns of habitat association at this scale may be related to physical 
and biological characteristics of the habitats themselves.

Processes which establish observed patterns of distribution have been reviewed by Williams (1991), who suggested that adult distributions reflected recruitment events. However, the extent to which recruitment patterns are modified by ontogenetic shifts in habitat is unclear. The third objective of this study was to examine ontogenetic patterns of habitat use by reef fishes, to determine the degree to which adult abundances reflect spatial patterns of recruitment.

Wrasses (Family Labridae) were selected for this study because they are a conspicuous and important component of the ichthyofauna on coral reefs throughout the world (Thresher 1991). This is especially true on the GBR, where they are the second most speciesrich family (Randall et al. 1990) and one of the 6 most abundant families by weight (Williams \& Hatcher 1983). With one possible exception (Pseudodax moluccanus; G.P. Jones pers. comm.), labrids are exclusively carnivores and represent a dominant group of benthic carnivores on coral reefs (Williams \& Hatcher 1983). Thcy include both generalist species which feed on a range of invertebrates (e.g. Thalassoma Iunare), and specialist feeders such as the cleaner fish Labroides dimidiatus and those which feed exclusively on coral polyps or mucus (e.g. Labropsis australis and Labrichthyes unilineatus; see Randall et al. 1990).

In order to address the objectives of this study, I did a detailed survey of the distribution and abundance of wrasses in a range of habitats, locations and times using visual census techniques. Many types of visual census techniques have been proposed for describing the distribution and abundance of reef fishes (Brock 1954, Jones \& Thompson 1978, DeMartini \& Roberts 1982, Kimmel 1985, Thresher \& Gunn 1986), and methods used vary with the aims of the project (Bellwood \& Alcala 1988). I used strip transects in this study, because they have been demonstrated to provide good quantitative estimates of the distribution and abundance of many other families of mobile reef fishes, which are diurnally active and conspicuous in both colouration and behaviour (Choat \& Bellwood 1985, Fowler 1987, Lincoln Smith 1988, 1989, McCormick 1989). However, since previous studies have demonstrated that the precision of these techniques are dependent on the methods used and the nature of the study species (Sale \& Sharp 1983, Fowler 1987, Bellwood \& Alcala 1988, Lincoln Smith 1988, 1989), a pilot study was done to determine the methods that were appropriate for censusing adult labrids. In this pilot study, I tested methods which have been described as important sources of bias in past studies, including transect dimensions, observer swimming speed, accuracy of underwater size estimation and experimental design (Underwood 1981, Sale \& Sharp 1983, Bell et al. 1985, Andrew \& Mapstone 1987, Fowler 1987, Lincoln Smith 1988, 1989).

\section{MATERIALS AND METHODS}

This study was divided into 3 sections: (1) a detailed description of each habitat zone, (2) an outline of the pilot study of visual census techniques, and (3) a description of the spatial and temporal patterns of distribution and abundance of fishes among habitat zones. In this last section, I also examined the degree to which recruitment patterns appeared important in structuring patterns of habitat use, by comparing the distribution and abundance of adults and recruits.

Description of study sites and habitat zones. This study was done at 3 sites (separated by 0.5 to $1.5 \mathrm{~km}$ ) on the fringing reef on the northeastern side of Lizard Island, northern GBR (14 $38^{\prime} \mathrm{S}, 145^{\circ} 24^{\prime} \mathrm{E}$; see Fig. 1). I chose these sites because they were areas of welldeveloped continuous reef tracts where exposure to the prevailing southeast winds and tidal currents was

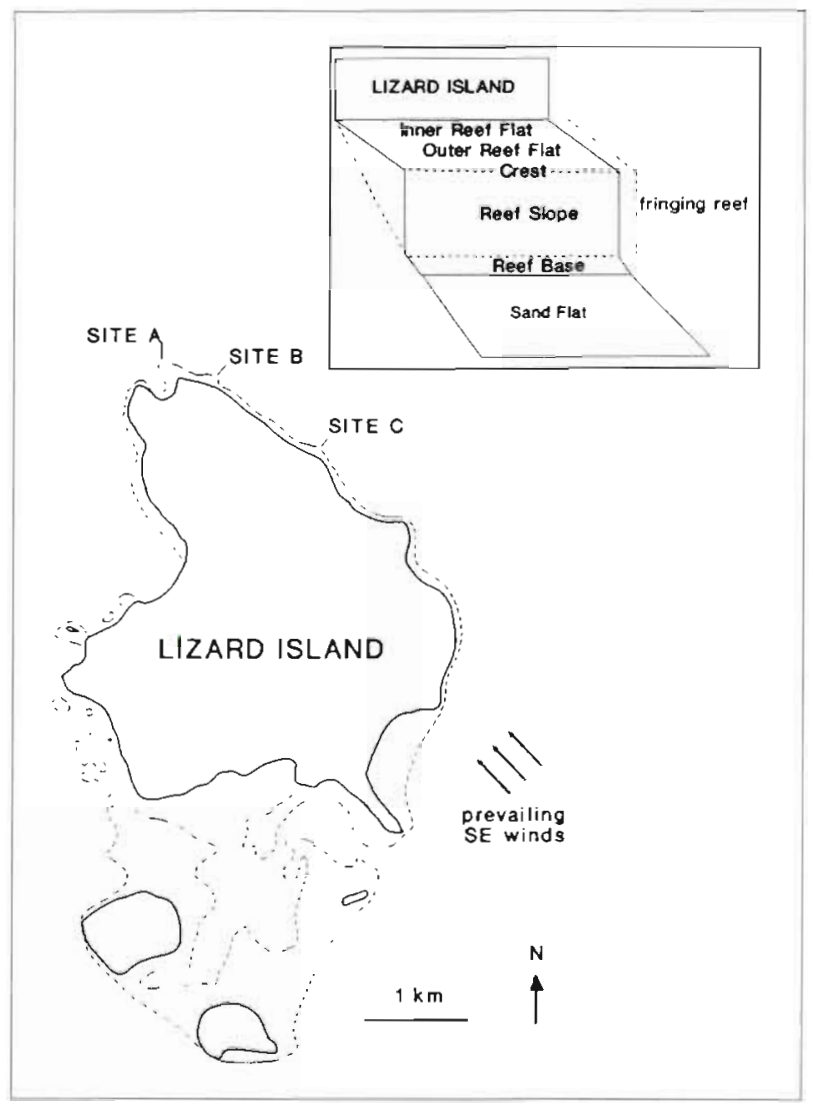

Fig. 1. Location of study sites at Lizard Island, northern Great Barrier Reef, and the position of 6 habitat zones on the reef profile at these sites (see inset) 
Table 1. Physical characteristics (depth and wave exposure) of 6 habitat zones at 3 study sites

\begin{tabular}{|lcc|}
\hline Habitat zone & Depth $(\mathrm{m})$ & Wave exposure \\
\hline Inner reef flat & $0.0-1.5$ & Low to high \\
Outer reef flat & $0.0-1.5$ & Low to high \\
Crest & $0.0-3.0$ & Low to high \\
Reef slope & $2.0-20.0$ & Low to moderate \\
Reef base & $5.0-20.0$ & Nil to low \\
Sand flat & $6.0-20.0$ & Nil to low \\
\hline
\end{tabular}

moderate. Reef profile, aspect, exposure and topography of these sites have been described by Choat \& Bellwood (1985).

The reef at these sites can be divided into 6 recognisable habitat zones, which differ in their position on the reef profile, depth and degree of wave exposure (Fig. 1, Table 1). The inner reef flat is located immediately adjacent to the shore of the island, and is littered with large granite boulders. The crest is defined as the seaward edge of the reef flat where the reef edge drops off into deeper water. The outer reef flat is situated between the inner reef flat and the crest. The reef slope descends at a slope of 50 to $90^{\circ}$ from the crest to the reef base, where it joins the sand flat which stretches away toward open water.

The biological characteristics of these zones, which may influence habitat use by labrid fishes, were described in January 1992. To do this I used a modification of the point-based method developed by Wiens \& Rotenberry (1981), which provided an estimate of biological substratum characteristics (percentage cover of different substrata and substratum diversity) and surface heterogeneity (substratum complexity). Five $50 \mathrm{~m}$ transects were laid consecutively in each of the 6 habitat zones at each site. At fifty $1 \mathrm{~m}$ intervais along each transect, a $2 \mathrm{~m}$ transect was run perpendicular to the tape. Three points were sampled along each $2 \mathrm{~m}$ transect, which yielded 150 sample points per $50 \mathrm{~m}$ transect.

At each point, the substratum was recorded as belonging to one of 15 categories: non-living (reef matrix, sand and rubble), crevice ( $>1 \mathrm{~m}$ deep), massive coral, digitate coral, plate coral, branching coral, encrusting coral, soft coral, foliaceous coral, free-living coral, gorgonian, hydrozoan, sponge, macroalgae and others (zooanthids, ascidians and clams). The height of the substratum above the reef platform and the number of contacts or 'hits' above the substratum on a vertical line through the object (Wiens \& Rotenberry 1981) were also recorded at each point. In combination, these measures enabled me to describe the biological characteristics of each transect. Percentage cover of each substratum category was calculated as the percentage of the points on each transect that were occupied by each substratum category, and substratum diversity $\left(N_{1}\right)$ was calculated as the diversity of cover of substratum categories, using the formula:

$$
N_{1}=\exp \left(-\Sigma p_{i} \ln p_{l}\right)
$$

where $p_{i}$ is the proportional coverage of the $i$ th substratum category (Wiens \& Rotenberry 1981). Substratum structural complexity was calculated as the average number of contacts per $10 \mathrm{~cm}$ above the basal substratum.

The influence of site $(n=3)$ and habitat zone $(n=6)$ on percentage cover of living substratum, substratum diversity and substratum complexity was tested using a 2-way fixed factor analysis of variance for each characteristic. Benthic assemblages were then compared graphically among locations (habitat zones at each site) using a canonical discriminant analysis on the percentage cover of each substratum type. Confidence intervals for centroid means were calculated using the formula:

$$
\left(\chi^{2} 2,0,05 / n\right)^{1 / 2}
$$

(Seber 1984), and structure coefficients were used to work out angles of contribution for the biplot.

Pilot study of visual census methods for fish surveys. Sixteen combinations of transect dimensions $(10,20,30$ and $50 \mathrm{~m}$ lengths and $1,2,3$ and $5 \mathrm{~m}$ widths) were tested on the crest at Site A (Fig. 1) in August 1990. Five replicate transects of each size were done by counting and estimating the total length of each labrid along the transect, while simultaneously measuring the length (using a $50 \mathrm{~m}$ tape) and width (using my known body proportions) of the transect. A standardised swimming speed of $60 \mathrm{~s}$ per $10 \mathrm{~m}^{2}$ was used, and all individuals $<25 \mathrm{~mm}$ total length (TL) were excluded from the count. All counts were done between 08:00 and 17:00 h to ensure spawning times were excluded.

The precision of labrid density estimations (number per $10 \mathrm{~m}^{2}$ ) for each transect size was calculated using the formula:

$$
\text { precision }=\text { standard error } / \text { mean }
$$

(Andrew \& Mapstone 1987). A 2-way analysis of variance was then done to determine if the length or width of the transect had a significant effect on the recorded density of labrids using transformed data $[\sqrt{(x+1 / 2)]}$ to homogenise variances.

The influence of observer swimming speed on the precision of the counts was examined by comparing the precision of five $50 \times 3 \mathrm{~m}$ transects, which I swam at each of 3 speeds: 30,60 and $90 \mathrm{~s}$ per $10 \mathrm{~m}^{2}$. I also measured the accuracy of visually estimating fish lengths underwater by first estimating the size of individuals, then capturing them with a small barrier net and measuring their actual sizes.

After choosing the survey methods (see 'Results': five $50 \times 3 \mathrm{~m}$ transects per habitat per site; speed $=60 \mathrm{~s}$ 
per $10 \mathrm{~m}^{2}$ ), I tested the technique in 6 habitat zones at 3 sites to determine if the desired level of precision of the technique was maintained in a variety of situations. The number of replicate transects required to maintain an acceptable level of precision $(0.2$; see Andrew \& Mapstone 1987) of the technique in each zone at each site was then calculated using the formula:

number of replicates $=$ $[\text { standard deviation/ }(\text { precision } \times \text { mean })]^{2}$

(see Andrew \& Mapstone 1987).

Spatial, temporal and ontogenetic patterns of habitat use. Using methods selected in the pilot study (see 'Pilot study' above), the spatial patterns of distribution and abundance of labrids were surveyed in 6 habitat zones at 3 sites in January 1992. Transects were the same as those used to describe habitat features (see 'Description of study sites and habitat zones' above). Only adults were included in the analysis, which I defined as individuals that were more than one-third of the maximum TL of each species (as recorded in Randall et al. 1990). Most species could be identified by sight in the field, although one group of closely related species (Halichoeres margaritaceus, $H$. nebulosus and $H$. miniatus) were difficult to separate, and were lumped together as Halichoeres spp.

Labrid density and diversity were determined for each habitat zone at each site. Labrid diversity was calculated using the same formulae used to calculate substratum diversity (see Eq. 1 above). The influence of site $(n=3)$ and zone $(n=6)$ on labrid density and diversity was tested using a 2-way fixed factor analysis of variance for each characteristic. Data were transformed $[\log (x+1)]$ for labrid density to homogenise variances. The relationship between each of 3 substratum characteristics (percentage live substratum, substratum diversity and substratum complexity) and labrid density and diversity was examined using Pearson's correlation coefficients.

Spatial patterns of habitat use were examined for each of the 8 most abundant species (see 'Results'), because they were present in sufficient numbers to provide powerful estimates of their patterns of distribution and abundance. These species were then used to compare the labrid assemblages graphically among locations (habitat zones at each site) using a canonical discriminant analysis (see Eq. 2 above).

Temporal patterns of habitat use were examined by repeating the habitat surveys at 2 sites (Sites A \& B; Fig. 1) on 5 occasions over 3 yr, encompassing both summer and winter austral seasons (August 1990, January 1991, July 1991, February 1992 and February 1993). A correspondence analysis was then used to graphically determine if patterns of habitat use by abundant species were consistent through time. This analysis used chi-squared distances to separate habitat zones by species, and was used because of the large numbers of zeros in the data set where species did not occur in some habitats through time (Greenacre 1984, B. McArdle pers. comm.).

Ontogenetic shifts in habitat use were examined by comparing patterns of distribution and abundance of adults and recruits of each of the 8 abundant species. I did this by repeating the surveys for both adults and recruits in all habitats and sites in February 1992. Narrower transects $(50 \times 1 \mathrm{~m})$ were used for the recruits because they were smaller and more cryptic than adults. Recruits were identified by their appearance (size and colouration) and cryptic behaviour.

\section{RESULTS}

\section{Description of habitat zones}

Biological characteristics differed among habitat zones. Percentage cover of living substratum and substratum diversity were each significantly different among habitat zones but not among sites (Table 2 , Fig. 2). Both measures varied in a unimodal gradient from the inner reef flat to the sand flat, and were low on the inner reef flat, reef base and sand flat, and high on the outer reef flat, crest and reef slope. Multiple comparisons (Tukey's test) revealed that each of these characteristics differed among all zones, except the

Table 2. Two-way fixed factor analysis of variance testing of the influence of site and zone on 3 habitat characteristics: percentage cover of living substratum, substratum diversity and substratum complexity. Data were transformed $[\log (x+1)]$ to conform with the assumptions of the analysis

\begin{tabular}{|lrrrr|}
\hline Source & df & MS & \multicolumn{1}{c|}{$F$} & \multicolumn{1}{c|}{$p$} \\
\hline Percentage cover & & & & \\
Site & 2 & 0.0010 & 2.52 & 0.0856 \\
Habitat zone & 5 & 0.0700 & 169.58 & $<0.0001$ \\
Site $\times$ Zone & 10 & 0.0007 & 1.94 & 0.0525 \\
Error & 72 & 0.0004 & & \\
Total & 89 & & & \\
Diversity & & & & \\
Site & 2 & 0.0022 & 1.00 & 0.3746 \\
Habitat zone & 5 & 0.4175 & 193.91 & $<0.0001$ \\
Site $\times$ Zone & 10 & 0.0036 & 1.67 & 0.1048 \\
Error & 72 & 0.0022 & & \\
Total & 89 & & & \\
Complexity & & & & \\
Site & 2 & 0.0182 & 7.47 & 0.0013 \\
Habitat zone & 5 & 0.0301 & 12.35 & $<0.0001$ \\
Site $\times$ Zone & 10 & 0.0075 & 3.09 & 0.0026 \\
Error & 72 & 0.0024 & & \\
Total & 89 & & & \\
\hline
\end{tabular}



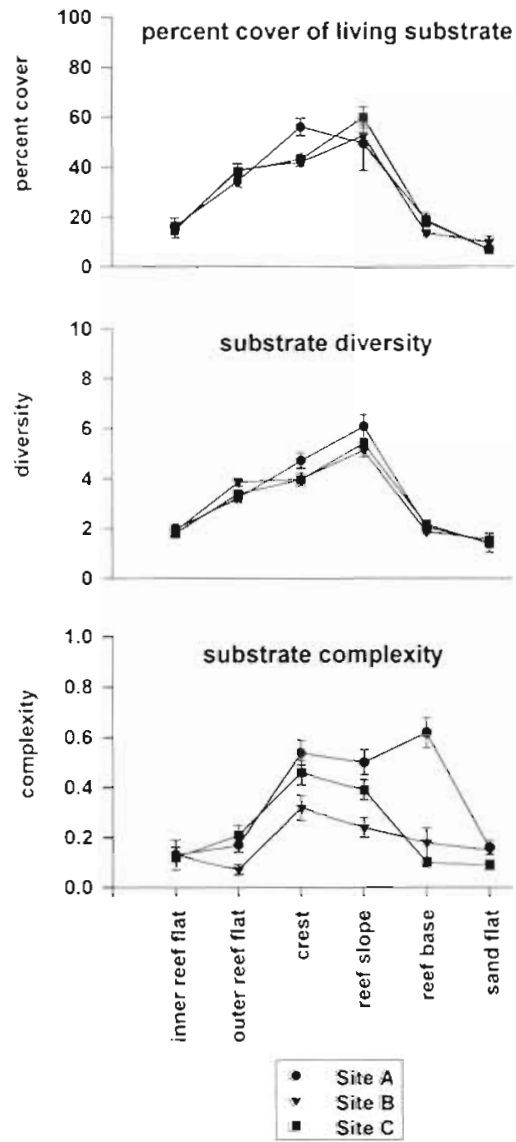

Fig. 2. Mean ( \pm SE) percentage cover of living substratum, substratum diversity and substratum complexity of each habitat zone at each site $(n=5)$

inner reef flat and the reef base. In contrast, there was a significant interaction among sites and habitats for substratum complexity. This was because substratum complexity was high at the reef base at Site A, and low in this habitat at the other 2 sites.

The benthic assemblages within habitat zones were distinctly different. This was confirmed by the canonical discriminant analysis which found that the percentage cover of 13 substratum types differed among locations (Pillai's Trace $=3.3461, p<0.0001$ ). Most of the variation among locations appeared to be associated with habitat zone, since locations grouped together into groups by habitat zones rather than by site (Fig. 3). The percentage cover of living substratum types differed among each of 3 habitat zones: crests, outer reef flats and reef slopes (see Fig. 4 also). Crests were characterised by a moderate cover of digitate and branching coral, as well as plate coral at Site A only. Outer reef flats were also characterised by a low cover of digitate, branching, plate and massive coral, except at Site C, where soft coral was also important. Reef slopes were characterised by massive

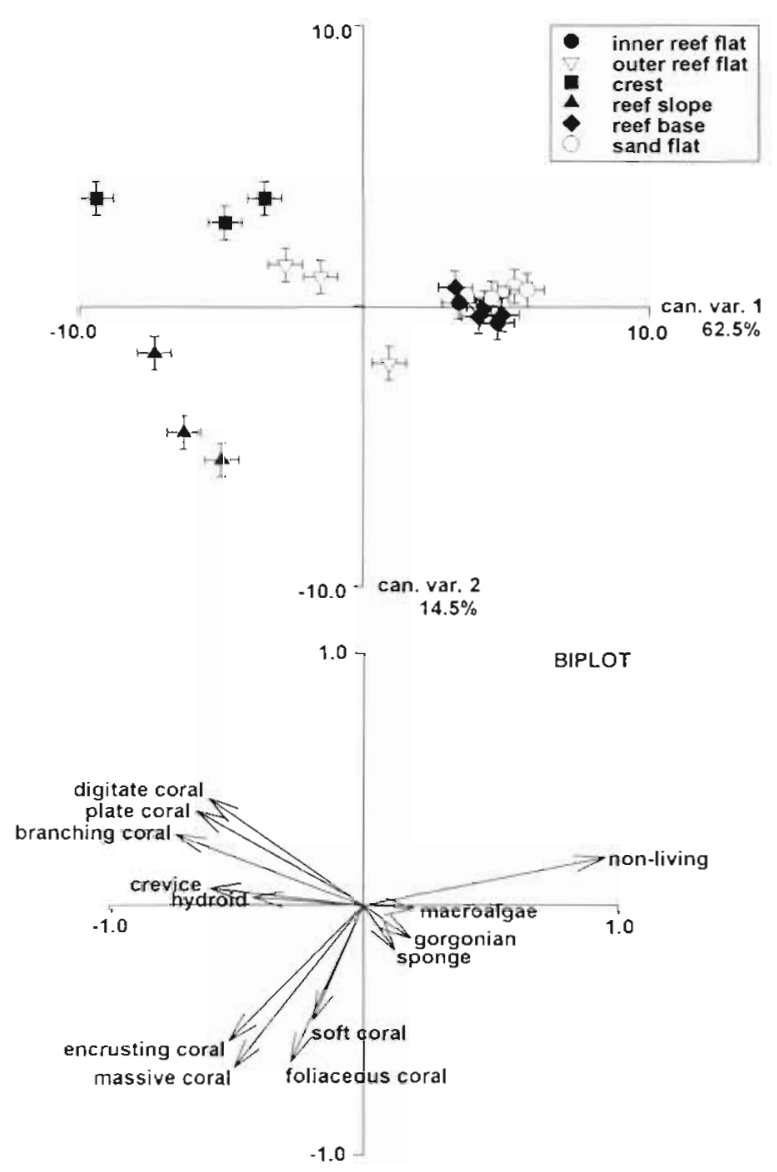

Fig. 3. Canonical discriminant analysis of substratum types at 6 habitat zones at each of 3 sites. Points are centroid means for each habitat per site, and bars represent $95 \%$ confidence limits $(n=5)$. Biplot shows the magnitude and direction of the contribution of each substratum category towards the separation of groups

coral, encrusting, soft and branching coral. The inner reef flat, reef base and sand flat all differed from the other habitat zones, because of their dominance by non-living substratum.

\section{Pilot study of visual census methods for fish surveys}

The pilot study identified methods which were most appropriate for surveying wrasses: 5 replicate $50 \times 3 \mathrm{~m}$ transects per habitat zone, done at an observer swimming speed of $60 \mathrm{~s}$ per $10 \mathrm{~m}^{2}$. All 16 transect sizes showed an acceptable level of precision $(\leq 0.2)$, with the greatest precision $(0.07)$ attained by 4 transect sizes: $10 \times 3,20 \times 3,50 \times 3$ and $50 \times 1 \mathrm{~m}$. Transect width had a significant effect on the density of labrids counted but transect length did not (Table 3 ). Of these sizes, $50 \times 3 \mathrm{~m}$ transects were selected for 2 reasons First, a width of $3 \mathrm{~m}$ was chosen because it showed 


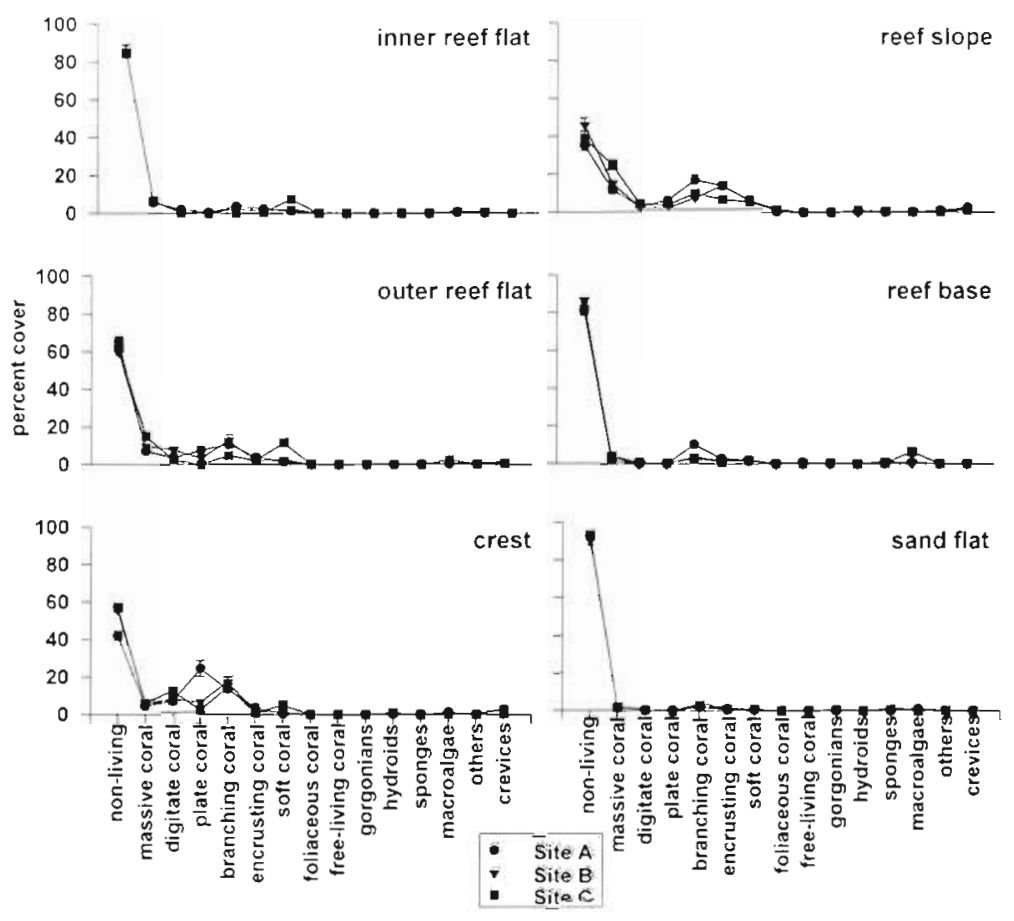

Fig. 4. Mean $( \pm \mathrm{SE})$ percentage cover of each substratum type in each habitat zone at each of 3 study sites $(n=5)$

consistently higher levels of precision (range $=0.07$ to 0.11 ) than did a width of $1 \mathrm{~m}$ (range $=0.07$ to 0.20 ). Second, a length of $50 \mathrm{~m}$ was chosen because larger study units are more likely to cover all. microhabitats and include rare species (Kimmel 1985, A. Green pers. obs.), as well as being larger in size than the home range or spatial distribution patterns of most species (see Eckert 1985, Andrew \& Mapstone 1987).

I selected an observer swimming speed of $60 \mathrm{~s}$ per $10 \mathrm{~m}^{2}$ for future surveys, because it provided a more precise estimate of labrid density (precision $=0.05$ ) than did the other 2 speeds I tested: 30 and 90 s per 10 $\mathrm{m}^{2}$ (precision of 0.11 and 0.12 respectively). Precision was probably highest at this speed because it was fast enough to include all individuals and to avoid counting highly mobile individuals more than once (Lincoln

Table 3. Two-way fixed factor analysis of variance testing of the influence of transect length and width on the density of labrids recorded on the crest at Site $A$. Data were transformed

$[v(x+1 / 2)]$ to conform with the assumptions of the analysis

\begin{tabular}{|lrrrr|}
\hline Source & df & MS & \multicolumn{1}{c|}{$F$} & \multicolumn{1}{c|}{ p } \\
\cline { 1 - 3 } Length & 3 & 0.12 & 1.47 & 0.2309 \\
Width & 3 & 1.39 & 16.34 & $<0.0001$ \\
Leagth $\times$ Width & 9 & 0.10 & 1.19 & 0.3159 \\
Error & 64 & 0.09 & & \\
Total & 79 & & & \\
\hline
\end{tabular}

Smith 1988), but slow enough to minimise the disturbance to the study species (Brock 1982, Fowler 1987).

I also confirmed that reliable estimates of fish sizes could be obtained by estimating their sizes underwater, with a significant correlation $\left(r^{2}=0.9879, n=112, p<0.0001\right.$, slope $=1.01$ ) detected between estimated and actual TL of 112 individuals of 10 species. Size estimation was closer to actual size for smaller individuals $(<10 \mathrm{~cm} \mathrm{TL})$, and became slightly less reliable as the size of the fish increased. However, when averaged over all individuals, the mean error of the technique was small when expressed as a percentage of the TL of the individuals (mean percent error $=3.6 \%, \mathrm{SE}=0.60, \mathrm{n}=$ 112).

The pilot study also confirmed that the chosen methods maintained an acceptable level of precision in most situations. A precision of $<0.2$ was attained for these methods in dil of the 6 habitat zones at each site, except for the inner reef flat at Sites A and B (precision of 0.26 and 0.24 respectively). Five replicate transects were adequate to attain the desired level of precision in 5 of the 6 habitat zones. However, 8 or 9 replicates were necessary to attain this level of precision on the inner reef flat at Sites $A$ and $B$, because of the patchy aggregations of abundant species such as Halichoeres spp., and highly mobile groups of Stethojulis bandanensis. Similarly, variation in precision among sites in other habitat zones (e.g. crest), was caused by patchy aggregations of abundant species such as Thalassoma hardwicke. Unfortunately, the number of transects to be used in future surveys could not be extended to 9 , because of time and space constraints (study sites were $<300 \mathrm{~m}$ long). So I decided to continue using 5 replicates transects in future surveys, since they produce an acceptable level of precision in most situations. As such, it must be acknowledged that surveys of the inner reef flat may not yield precise estimates of labrid densities using the selected survey techniques, and should be interpreted with caution.

\section{Spatial, temporal and ontogenetic patterns of habitat use}

This study found that the biological characteristics of the labrid assemblages were distinctly different in each habitat zone. Both labrid density and diversity differed significantly among habitat zones (Table 4, Fig. 5). Multiple comparisons (Tukey's test) revealed that labrid 
Table 4. Two-way fixed factor analysis of variance testing of the influence of site and zone on labrid density and diversity. Data for labrid density were transformed $[\log (x+1)]$ to conform with the assumptions of the analysis

\begin{tabular}{|lrrrr|}
\hline Source & df & MS & F & \multicolumn{1}{c|}{$\mathrm{p}$} \\
\hline Density & & & & \\
Site & 2 & 0.01 & 0.25 & 0.7838 \\
Habitat zone & 5 & 0.53 & 18.46 & $<0.0001$ \\
Site $\times$ Zone & 10 & 0.05 & 1.82 & 0.0727 \\
Error & 72 & 0.03 & & \\
Total & 89 & & & \\
Diversity & & & & \\
Site & 2 & 2.04 & 1.04 & 0.3608 \\
Habitat zone & 5 & 4.75 & 2.41 & 0.0438 \\
Site $\times$ Zone & 10 & 2.81 & 1.43 & 0.1842 \\
Error & 72 & 1.97 & & \\
Total & 89 & & & \\
& & & & \\
\end{tabular}

density was significantly lower on the reef slope than in either of the other 5 habitat zones, and significantly lower on the sand flat than it was on the outer reef flat, crest and reef base (but not on the inner reef flat or the reef slope). Multiple comparisons also revealed that labrid diversity was significantly different between the inner and outer reef flats only. Labrid density and diversity each showed only weak correlations with percentage living substratum (Table 5), substratum diversity (Table 5), substratum complexity (Table 5) or with each other $\left(r^{2}=0.15, n=90, p<0.1718\right)$

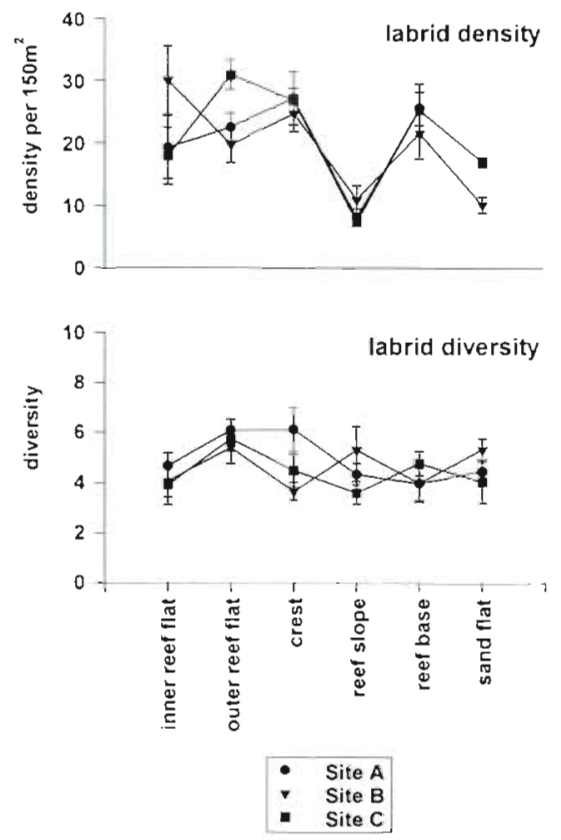

Fig. 5. Mean ( \pm SE) density and diversity of labrids in each of 6 habitat zones at 3 sites at Lizard Island $(n=5)$
Table 5. Pearson's correlation $\left(\mathrm{r}^{2}\right)$ between labrid density and diversity and each of 3 substratum characteristics: percentage living substratum, substratum diversity and substratum complexity $(n=90)$

\begin{tabular}{|cccc|}
\hline $\begin{array}{c}\text { Percentage living } \\
\text { substratum }\end{array}$ & $\begin{array}{c}\text { Substratum } \\
\text { diversity }\end{array}$ & $\begin{array}{c}\text { Substratum } \\
\text { complexity }\end{array}$ \\
\hline Labrid density & -0.14 & -0.22 & 0.06 \\
& $(p<0.1822)$ & $(p<0.0380)$ & $(p<0.6053)$ \\
Labrid diversity & 0.13 & 0.10 & -0.02 \\
& $(p<0.2100)$ & $(p<0.3503)$ & $(p<0.8421)$ \\
\hline
\end{tabular}

A large number of labrid species (64) were recorded in 5 surveys over 3 yr at Lizard Island. Thirty-eight species (1804 individuals) were recorded in a single survey (February 1992) of all habitat zones (Fig. 6), of which 8 were abundant ( $\mathrm{n}>5 \%$ of total), 6 were common $(1 \%<n<5 \%$ of total) and 24 were rare $(n<1 \%$ of total number of individuals)

Seven of the 8 abundant species showed strong patterns of habitat use associated with depth (Fig. 7). Halichoeres spp., Stethojulis bandanensis, Thalassoma hardwicke and $T$. jansenii were most abundant in the shallow habitats, while Coris schroederi, H. melanurus and $T$. lunare were most abundant in the deep habitat zones. Within depth ranges, species differed among habitats in terms of their relative abundance. Only 1 species, Labroides dimidiatus, occurred in similar densities in all habitat zones.

Each habitat zone had a distinctive assemblage of the abundant species. This was confirmed by the canonical discriminant analysis, which showed that the assemblages of these species varied among locations (Pillai's Trace $=5.07, p<0.0001 ;$ Fig. 8). Most of the variation among locations appeared to be associated with habitat zone, since locations grouped together into groups by habitat zones rather than by site. Inner and outer reef flats differed from other habitats but not from each other, because they were both dominated by high densities of Thalassoma jansenii and Stethojulis bandanensis, as well as by Halichoeres spp. (especially the inner reef flat at Site C). However, the results for inner reef flats should be interpreted with caution, because the counts may be of low precision (see 'Pilot study' above). Crests differed from other habitats, because of a high density of $T$. hardwicke. The reef base and sand flat differed from other habitats, because of the high densities of $H$. melanurus, $T$. lunare and $C$. schroederi. These 2 habitats differed from each other at 2 sites, because of the higher and lower densities of $H$. melanurus and $C$. schroederi respectively on the reef base than the sand flat. In contrast, reef slopes were distinctive because of the low densities of all of these species. 
Ontogenetic changes in habitat use appeared to be the exception, rather than the rule. Most of the abundant species showed similar patterns of habitat use as both adults and recruits (Fig. 7): Coris schroederi, Halichoeres melanurus, Halichoeres spp., Stethojulis bandanensis, Thalassoma hardwicke and $T$. jansenii. However, 2 species did show ontogenetic shifts in habitat use, with recruits using a narrower range of habitats than adults. Labroides dimidiatus was most abundant on the 2 deeper habitats (reef slope and reef base) as recruits, and used shallower habitats more as adults. $T$. lunare was also most abundant on the reef slope as srecruits, but used deeper habitats more as adults.

Overriding patterns of habitat use by each of the 8 abundant species were consistent throughout the 3 yr and 2 seasons of the study, although the density of individuals in 'preferred' habitats sometimes varied over time, e.g. Thalassoma jansenii (Fig. 9). As a result, the assemblages that characterised each habitat zone were also consistent through time. This was demonstrated by the correspondence analysis, which showed that the labrid assemblages in each habitat zone grouped together through time (Fig. 10).

\section{DISCUSSION}

This study demonstrated that reef fishes (wrasses) show distinctive patterns of habitat use at a fine spatial scale. Most abundant species showed strong patterns

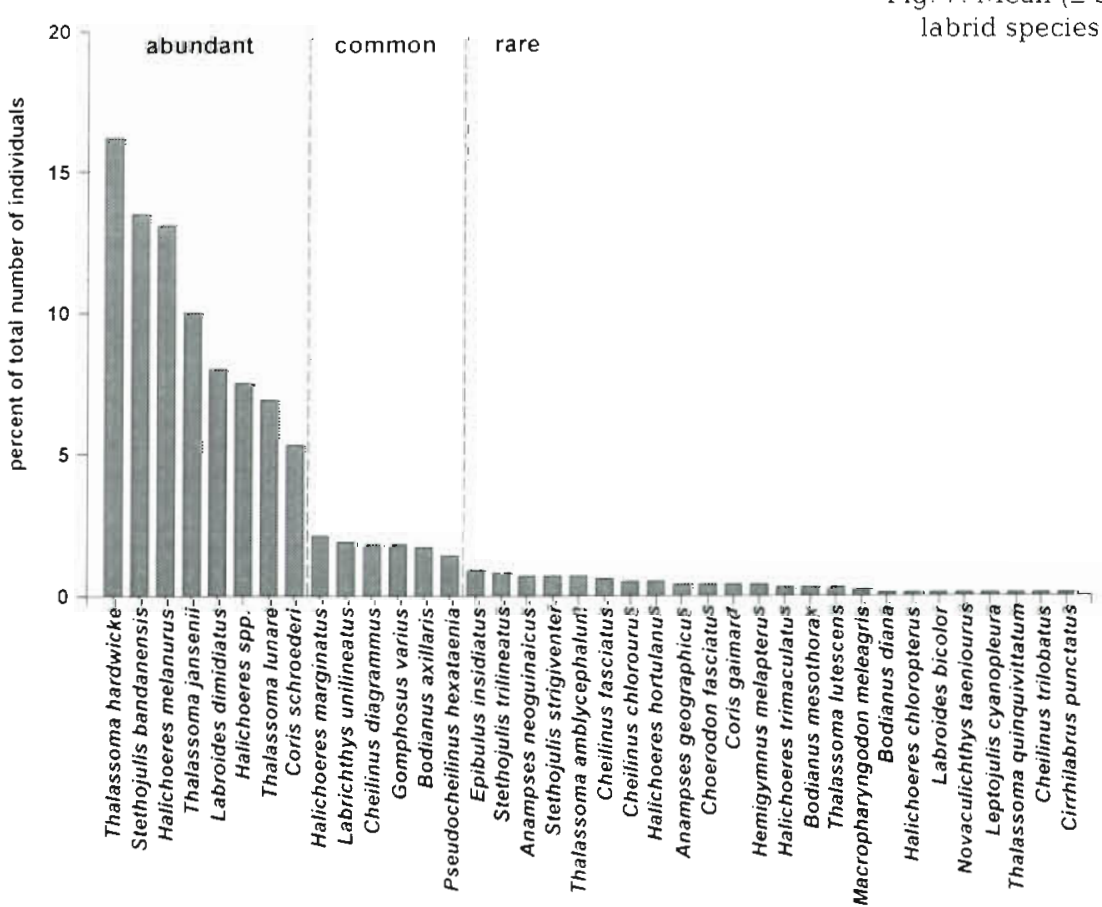

Fig. 6. Relative abundance of 38 labrid species on the oblique fringing reef on the northeastern side of Lizard Island $(\mathrm{n}=1804)$
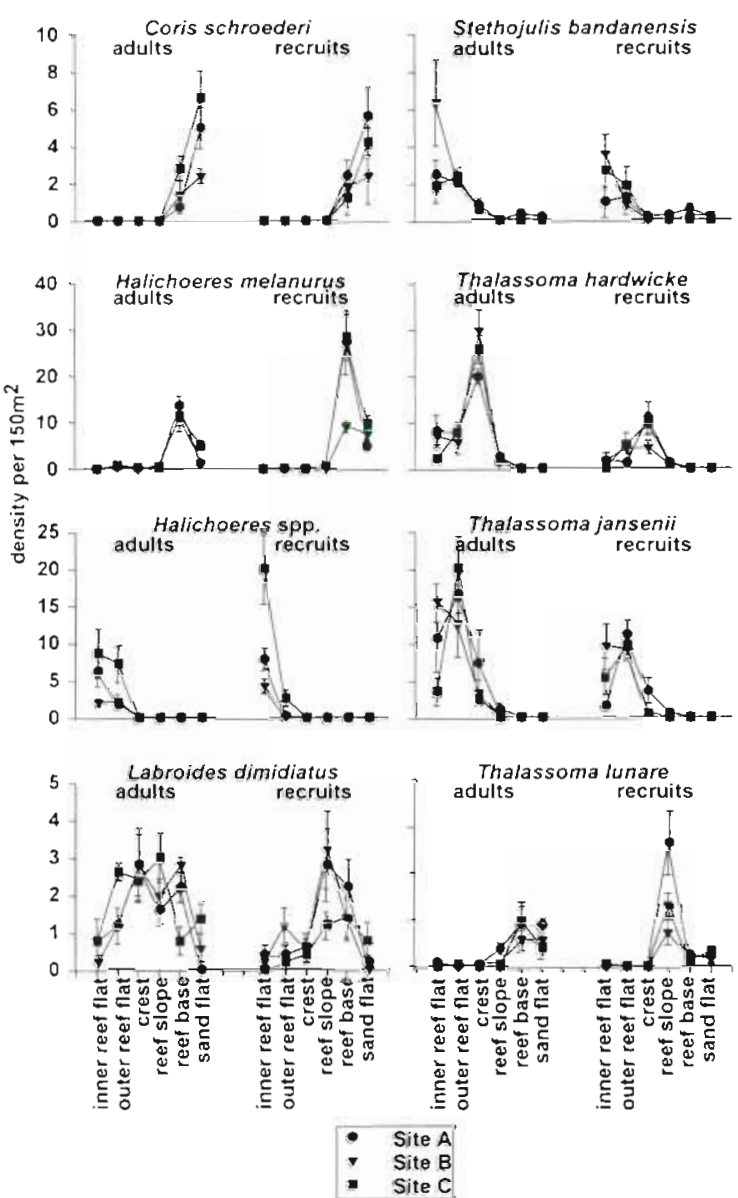

g. 7. Mean $( \pm \mathrm{SE}$ ) density of adults and recruits of each of 8 labrid species in 6 habitat zones at each of 3 sites $(n=5)$

of distribution and abundance among habitats, each being present in high densities in only 1 or 2 of the 6 habitat zones studied. As a result, each habitat zone comprised a unique assemblage of fishes, which was maintained at several locations along the reef. These fine-scale patterns of habitat use have also been found to be consistent at other reef exposures, and on other islands of the GBR (Green unpubl. data).

Depth appeared to be of overriding importance in determining patterns of habitat use, with most species occurring in either shallow (inner reef flat, outer reef flat or crest) or deep (reef base and sand flat) habitat zones. Within depth ranges, species differed in their relative abundance among habitat 

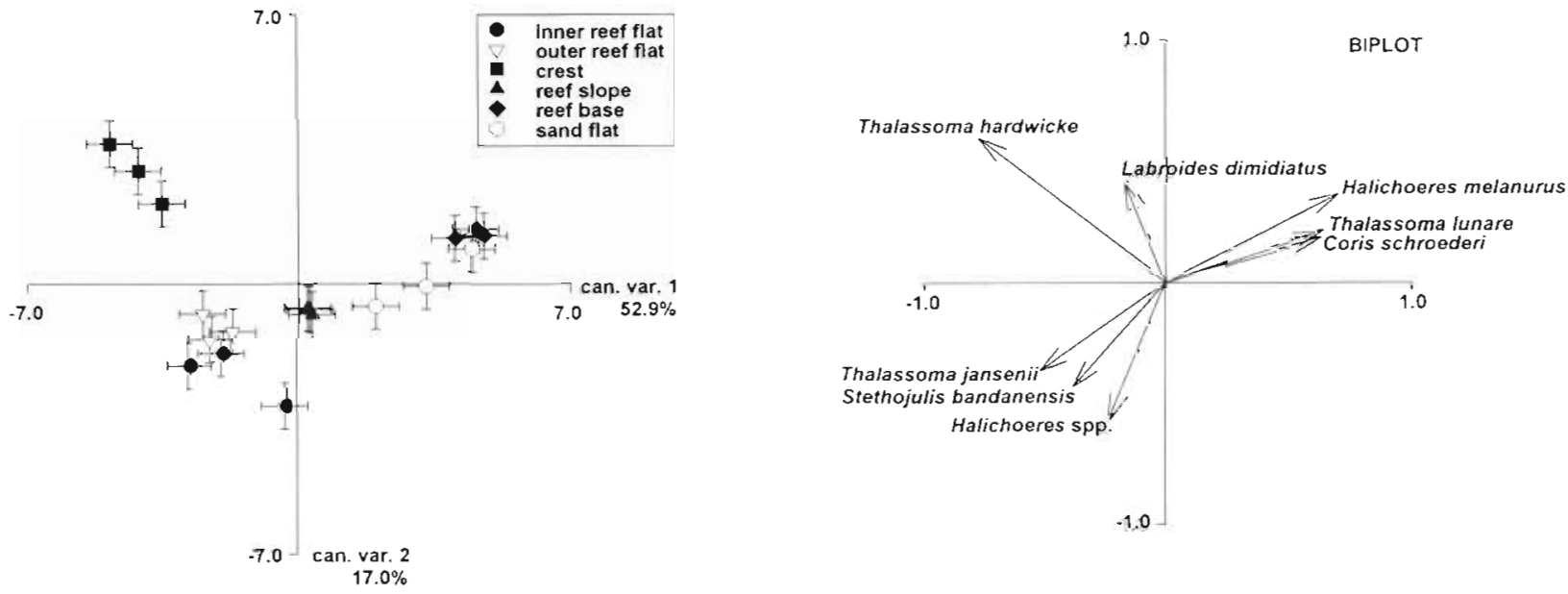

Fig. 8. Canonical discriminant analysis of the assemblages of abundant labrids in 6 habitat zones at each of 3 sites. Points are centroid means for each habitat per site, and bars represent $95 \%$ confidence limits $(n=5)$. Biplot shows the magnitude and direction of the contribution of each labrid species towards the separation of groups

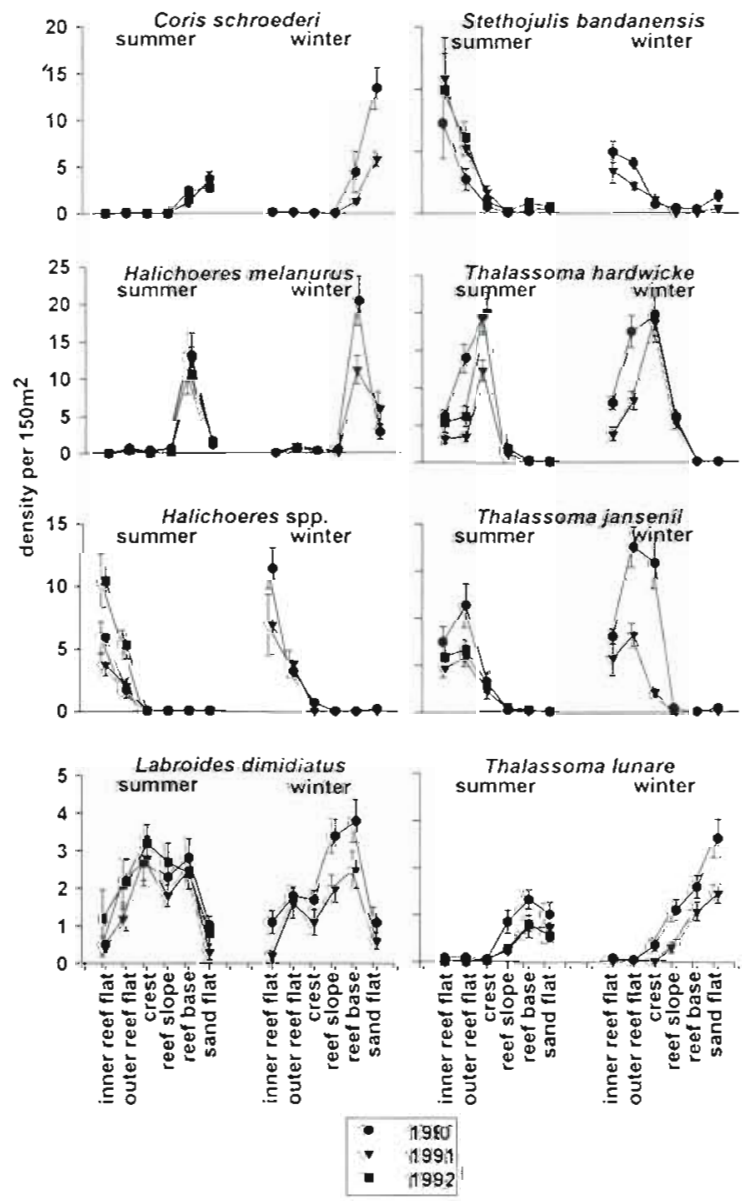

Fig. 9. Mean ( $\pm \mathrm{SE}$ ) density of each of 8 labrid species in 6 habitat zones on 5 occasions over 3 consecutive years and 2 seasons $(n=10)$
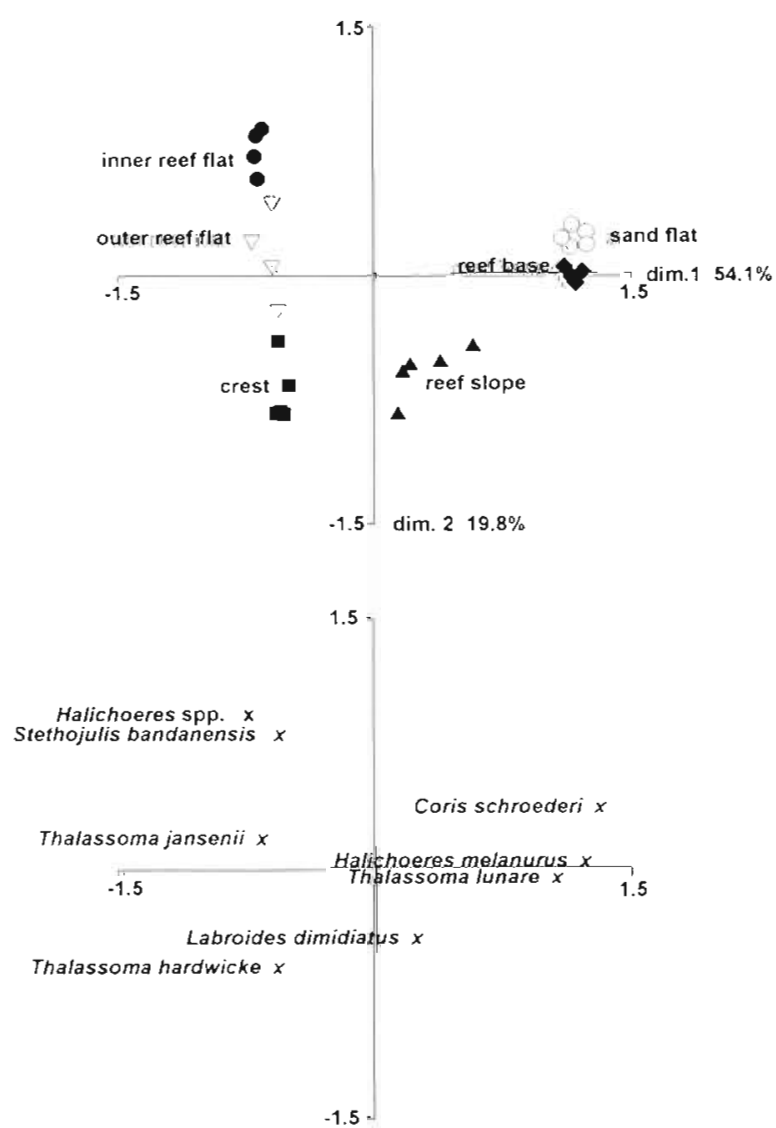

Fig. 10. Correspondence analysis of the relative abundance of 8 labrid species in 6 habitat zones on 5 occasions over 3 consecutive years 
zones. Only 1 species, Labroides dimidiatus, was ubiquitous and occurred in low densities in all habitat zones. No abundant species were present in high densities on the reef slopes, which may have been because the slopes were very steep in most places

No clear relationship was detected between labrid density or diversity and the biological characteristics of the habitat zones, including percentage cover of living substratum, substratum diversity and substratum complexity. These results are consistent with those of most previous studies, which have also failed to find a strong correlation between reef fish habitat association and specific substratum characteristics, except for some obligate corallivorous chaetodontids or small siteattached species (see review in Williams 1991). This may be because families such as labrids have large home ranges which may encompass a variety of habitat features, and may be unlikely to show strong association with specific habitat characteristics (Roberts \& Ormond 1987).

In this study, spatial patterns of habitat use by reef fishes were found to be consistent over $3 \mathrm{yr}$ and 2 seasons (summer and winter). Temporal variation in the assemblages associated with different habitats was limited to small-scale variations in the density of individual species within habitat zones, and did not affect the overall pattern of habitat use by these fishes. Such temporal consistency in patterns of habitat use has also been reported for other tropical and temperate families of reef fish (Choat 1982, Williams 1986, Fowler 1990), and may represent a generalised pattern of reef fish distribution and abundance.

Fine-scale spatial patterns of habitat use by reef fishes may be the result of a number of processes operating at this scale. In this study, the degree to which spatial patterns of habitat use by adults reflected patterns of recruitment varied among species. Ontogenetic changes in habitat use were more the exception than the rule, with 6 of the 8 abundant species showing similar patterns of habitat use as adults and recruits. In the past it has been suggested that these results infer that recruitment patterns may be important in structuring patterns of habitat use by many reef fishes (see Williams 1980, 1991, Williams \& Sale 1981, Eckert 1985). However, similar patterns of habitat use by recruits and adults could also occur as a result of differential survival in different habitats, in combination with a subsequent redistribution of individuals among habitats. To date, it has not been possible to discriminate between the relative importance of recruitment and post-settlement processes in influencing patterns of habitat use by wrasses, since little is known of their post-settlement ecology in different habitats.

Nevertheless, the ontogenetic patterns of habitat use described in this study may provide some insight into the importance of these processes in determining habitat use by reef fishes. Many reef fishes show strong patterns of microhabitat selection as recruits (Sale et al. 1984), and ontogenetic shifts in habitat use, or the lack thereof, may reflect the availability of these 'preferred' microhabitats in adult habitats (see Victor 1986). In this study, the recruits of 2 species which showed ontogenetic shifts in habitat use, Thalassoma lunare and Labroides dimidiatus, are known to show microhabitat selection for substrata which were not readily available in adult habitats. These recruits prefer live branching coral or the holes underneath plate corals ( $T$. Iunare and L. dimidiatus respectively; Eckert 1985. Green unpubl, data), and these microhabitats were more abundant in the habitat used by recruits than they were in the adult habitats (Figs. $4 \& 8$ ). As the individuals of these species grow, their association with this type of microhabitat may weaken and the juveniles may move into adult habitats. Conversely, other species may not have shown ontogenetic shifts in habitat use because the microhabitats preferred by recruits were abundant within adult habitats. For exampie, Coris schroederi and Halichoeres melanurus recruits both show strong microhabitat selection for the macroalgae occurring within the territories of herbivorous damselfish (Green 1992) and dead substratum (Eckert 1985, Green unpubl. data), both of which are abundant within adult habitats (Green 1992, this study's Figs. $4 \& 8$ ). Hence, there may be no requirement for an ontogenetic shift in habitat use by these species. A similar argument can be invoked for $T$. hardwicke, T. jansenii and Halichoeres spp., whose recruits 'prefer' microhabitats that are readily available in adult habitats (live branching and plate coral for $T$. hardwicke, and dead substratum for $T$. jansenii and Halichoeres spp.: Green unpubl. data, see this study's Figs. 4 \& 8). However, since this conclusion is largely based on circumstantial evidence, a detailed study of the patterns of recruitment and post-settlement mortality and movement of these species in a range of habitats will be required to test this hypothesis.

Acknowledgements. I am grateful to J. H. Choat, P. Doherty, $M$. McCormick and an anonymous referee for reviewing this manuscript. I also thank N. Moltschaniwskyj and B. McArdle for statistical advice, and S. Greene, A. Newton, T Preen, K. Miller and K. Hall for field assistance. This work was supported by a Lizard Island Research Station Fellowship and an Australian Postgraduate Research Fellowship.

\section{LITERATURE CITED}

Andrew NI, Mapstone BD (1987) Sampling and the description of spatial pattern in marine ecology. Oceanogr Mar Brol A. Rev 25:39-90 
Bell JD, Craik GJS, Pollard DA, Russell BC (1985) Estimating length frequency distributions of large reef fish underwater. Coral Reefs 4:41-44

Bellwood DR, Alcala AC (1988) The effect of a minimum length specification on visual estimates of density and biomass of coral reef fishes. Coral Reefs 7:23-27

Brock RE (1982) A critique of the visual census method for assessing coral reef fish populations. Bull Mar Sci 32(1): $269-276$

Brock VE (1954) A preliminary report on a method of estimating reef fish populations. J Wildl Mgmt 18:297-308

Choat JH (1982) Fish feeding and the structure of benthic communities in temperate waters. A Rev Ecol Syst 13:423-449

Choat JH, Bellwood DR (1985) Interactions amongst herbivorous fishes on a coral reef: influence of spatial variation. Mar Biol 89:221-234

DeMartini EE, Roberts, D. (1982) An empirical test of biases in the rapid visual technique for species-time censuses of reef fish assemblages. Mar Biol 70:129-134

Doherty PJ, Williams DMcB (1988) The replenishment of coral reef fish populations. Oceanogr Mar Biol A Rev 26: $487-551$

Eckert GJ (1985) Population studies of labrid fishes on the southern Great Barrier Reef. PhD thesis, University of Sydney

Fowler AJ (1987) The development of sampling strategies for population studies of coral reef fishes. A case study. Coral Reefs 6:49-58

Fowler AJ (1990) Spatial and temporal patterns of distribution and abundance of chaelodontid fishes at One Tree Reef. southern GBR. Mar Ecol Prog Ser 64:39-53

Goldman B, Talbot FH (1976) Aspects of the ecology of coral reef fishes. In: Jones OA, Endean R (eds) Biology and geology of coral reefs. Academic Press, New York, p 125-154

Green AL (1992) Damselfish territories: focal sites for studies of the early life history of labroid fishes. Proc. 4 th Int Coral Reefs Symp 1:601-605

Greenacre MJ (1984) Theory and application of correspondence analysis. Academic Press, London

Jones GP (1988) Experimental evaluation of the effects of habitat structure and competitive interactions on the juveniles of two coral reef fishes. J Exp Mar Biol Ecol 123:115-126

Jones RS, Thompson MJ (1978) Comparison of Florida reef fish assemblages using a rapid visual technique. Bull Mar Sci 28:159-172

Kimmel JJ (1985) A new species-time method for visual assessment of fishes and its comparison with established methods. Environ Biol Fish 12(1):23-32

Lincoln Smith MP (1988) Effects of observer swimming speed on sample counts of temperate rocky reef fish assemblages. Mar Ecol Prog Ser 43:223-231

Lincoln Smith MP (1989) Improving multispecies rocky reef fish censuses by counting different groups of species using different procedures. Environ Biol Fish 26:29-37

Mapstone BD, Fowler AJ (1988) Recruitment and the structure of assemblages of fish on coral reefs. Trends Ecol Evol $3(21): 72-77$

This article was presented by D. M. Alongi (Senior Editorial Advisor), Townsville, Australia
McCormick MI (1989) Spatio-temporal patterns in the abundance and population structure of a large temperate reef fish. Mar Ecol Prog Ser 53:215-225

Randall JE, Allen GR, Steene RC (1990) Fishes of the Great Barrier Reef and Coral Sea. Crawford House Press. Bathurst

Roberts CM, Ormond RFG (1987) Habitat complexity and coral reef fish diversity and abundance on Red Sea fringing reefs. Mar Ecol Prog Ser 41:1-8

Sale PF, Sharp BJ (1983) Correction for bias in visual transect censuses of coral reef fishes. Coral Reefs $2: 37-42$

Sale PF, Douglas WA, Doherty PJ (1984) Choice of microhabitats by coral reef fishes at settlement. Coral Reefs 3 : 91-99

Seber GAF (1984) Multivariate observations. Wiley, New York

Talbot FH, Goldman G (1972) A preliminary report on the diversity and feeding relationships of the reef fishes of One Tree Island, Great Barrier Reef system. Proc 1st Int Symp Coral Reefs 1:425-442

Thresher RE (1991) Geographic variability in the ecology of coral reef fishes: evidence, evolution, and possible implications. In: Sale PF (ed) The ecology of fishes on coral reefs. Academic Press, Sydney, p 401-436

Thresher RE, Gunn JS (1986) Comparative analysis of visual census techniques for highly mobile, reef associated piscivores (Carangidae). Environ Biol Fish 17(2):93-116

Underwood AJ (1981) Techniques of analysis of variance in experimental marine biology and ecology. Oceanogr Mar Biol A Rev 19:513-605

Victor BC (1986) Larval settlement and juvenile mortality in a recruitment-limited coral reef fish population. Ecol Monogr 56(2): 145-160

Wiens JA, Rotenberry JT (1981) Habitat associations and community structure of birds in shrubsteppe environments. Ecol Monogr 51:409-422

Williams DM (1980) Dynamics of the pomacentrid community on small patch reefs in One Tree Lagoon (Great Barrier Reef). Bull Mar Sci 30:159-170

Williams DM (1982) Patterns in the distribution of fish communities across the central Great Barrier Reef. Coral Reefs $1: 35-43$

Williams DM (1986) Temporal variation in the structure of reef slope fish communities (central Great Barrier Reef): short-term effects of Acanthaster planci infestation. Mar Ecol Prog Ser 28:157-164

Williams DM (1991) Patterns and processes in the distribution of coral reef fishes. In: Sale PF (ed) The ecology of fishes on coral reefs. Academic Press, Sydney, p 437-474

Williams DM, Hatcher AI (1983) Structure of fish communities on outer slopes of inshore, mid-shelf and outer shelf reefs of the Great Barrier Reef. Mar Ecol Prog Ser 10 $239-250$

Williams DM, Sale PF (1981) Spatial and temporal patterns of recruitment of juvenile coral reef fishes to coral habitats within One Tree Lagoon, Great Barrier Reef. Mar Biol 65: $245-253$

Manuscript first received: November 10, 1994

Revised version accepted: August 24, 1995 